\title{
A Study of Impact Response and Its Numerical Study of Hybrid Polypropylene Fiber-Reinforced Concrete with Different Sizes
}

\author{
Ninghui Liang $\mathbb{D}^{1,2}$ Ru Yan $\mathbb{C}^{1,{ }^{1,2}}$ Xinrong Liu, ${ }^{1,2}$ Peng Yang, ${ }^{1,2}$ and Zuliang Zhong ${ }^{1,2}$ \\ ${ }^{1}$ College of Civil Engineering, Chongqing University, Chongqing, China \\ ${ }^{2}$ Key Laboratory of New Technology for Construction of Cities in Maintain Area, Ministry of Education, Chongqing, China
}

Correspondence should be addressed to Ninghui Liang; liangninghui0705@163.com

Received 24 May 2020; Revised 6 September 2020; Accepted 25 September 2020; Published 8 October 2020

Academic Editor: Michael Aizenshtein

Copyright $(0) 2020$ Ninghui Liang et al. This is an open access article distributed under the Creative Commons Attribution License, which permits unrestricted use, distribution, and reproduction in any medium, provided the original work is properly cited.

Compressive properties of hybrid polypropylene fiber-reinforced concrete (HPFRC) with different sizes of polypropylene fibers (PPFs) under the impact load $\left(10^{1} \sim 10^{2} / \mathrm{s}\right)$ were tested by using a $74 \mathrm{~mm}$ diameter various cross-section split-Hopkinson pressure bar (SHPB), in which the fiber content of fine PPFs was $0.9 \mathrm{~kg} / \mathrm{m}^{3}$ and that of coarse PPFs was $6.0 \mathrm{~kg} / \mathrm{m}^{3}$. The effect of strain rate and PPF hybridization on the impact characteristics of HPFRC was analyzed. It is found that dynamic compressive properties, including dynamic compressive strength, dynamic compressive strength increase factor (DCF), ultimate strain, and impact toughness, increased with the increase of strain rate. Meanwhile, both fine PPFs and coarse PPFs can enhance the impact strength of concrete, and an appropriate hybridization of two sizes of PPFs in concrete was more effective than the concrete reinforced with one size of PPF. Moreover, a modified constitutive model for HPFRC was proposed based on the Holmquist-Johnson-Cook (HJC) constitutive model. Then, the numerical study of SHPB tests for HPFRC was conducted based on the modified model, which showed that the modified HJC constitutive model could well describe the dynamic stress-strain relationship of HPFRC.

\section{Introduction}

The application of conventional fiber-reinforced concrete (FRC), including one type of fiber such as steel, polypropylene (PP, the most typical synthetic fiber), basalt, and carbon, has become a common method to improve the performance of concrete, which has been widely applied to many construction industries nowadays [1]. Meanwhile, the research has shown that the workability of hybrid fiberreinforced concrete (HFRC) is superior to FRC for fracture in concrete and merits improvement to the toughening mechanisms at various dimensional levels [2-5]. In recent years, PPF has attracted more and more attention for its significant advantages and is becoming an attractive alternative to the steel fiber [6-8]. On the contrary, many researchers focused on the hybridization of different types of fiber, such as the hybridization of steel and fine PP, which performs very well [9-12]. While the literature for studying the hybridization of different sizes of the same fiber was rare, the coarse PPF hybridized with the fine PPF in concrete will be a new approach to study the performance of HFRC.

In practical application, concrete-like materials will be inevitably subject to various kinds of dynamic loads, including earthquakes and explosions. Numerous researchers have performed research studies on the dynamic mechanical behavior of concrete-like materials $[13,14]$, in which the SHPB test has been widely used for evaluating its dynamic properties at a high strain rate between $10^{1}$ and $10^{3} \mathrm{~s}^{-1} 15$. Zhigang et al. [16] compared the impact response between steel-polypropylene hybrid fiber-reinforced concrete (HFRC) and steel fiber-reinforced concrete (SFRC), and the result indicated that HFRC performed better than SFRC in failure stress, peak strain, and peak toughness. Ibrahim et al. [17] investigated the stress-strain characteristics of steelpolypropylene-Kevlar HFRC composites. Fu et al. [18] studied the dynamic compressive mechanical behavior of basalt-polypropylene HFRC and found the addition of basalt-PP can significantly improve the strain rate effect of dynamic compressive strength. 
To summarize, it can be concluded that the dynamic properties of HFRC were sensitive to strain rate, and the proportion of the hybrid fiber can also affect its impact response. Dynamic constitutive models for concrete-like materials have been established in recent years, including the HJC model, Karagozian and Case (K\&C) model, Riedel-Hiermaier-Thoma (RHT) model, and Z-W-T model [19]. Ye et al. [20] proposed a nonlinear viscoplastic constitutive equation through the dynamic compressive tests on steel fiber concrete subjected to impact load. Yang et al. [21] proposed a damage constitutive model for multisize polypropylene fiber concrete under impact load. Overall, the HJC model is a typical model to study the impact behavior of concrete-like materials subjected to large strains, high strain rates, and high pressures and is modified to be widely applied to HFRC. Besides, in engineering design, numerical analysis is commonly applied to the simulation of engineering behavior and has been widely used to validate [22]. Through numerical calculation, the mechanical behavior of HFRC can be rapidly determined for use as the basis of better engineering design.

To further study fiber hybridization and its engineering application, the dynamic mechanical properties of HPFRC subjected to different impact loads with a various crosssection SHPB apparatus were investigated in this paper. The effect of strain rate and fiber hybrid quality ratio on the impact performance of HPFRC was analyzed and discussed. Then, a modified HJC dynamic damage constitutive model for HPFRC was established based on the original HJC model. Finally, LS-DYNA software was used to implement numerical simulation, whose numerical calculation results were in good agreement with the HPB test result.

\section{Experimental Procedures}

2.1. Materials. HPFRC was composed of cement, coarse aggregates, fine aggregates, water, fine PPF, and coarse PPF. Ordinary Portland cement type P.O 42.5 was used by the Chinese standard (GB 175-2009). Coarse aggregates were detritus of limestone gravels whose particle size was $5 \mathrm{~mm}$ to $10 \mathrm{~mm}$. Artificial sand was used as the fine aggregate whose fineness modulus was 3.1. Meanwhile, the content of polycarboxylic acid superplasticizer was $3.8 \mathrm{~kg} / \mathrm{m}^{3}$. In this study, two different sizes of PPFs were used, namely, fine PPF and coarse PPF. Figure 1 presents the used fine PPF and coarse PPF, and their physical properties are shown in Table 1. C30 strength grade concrete was adopted, which had six groups. All groups used the same mixture proportion, but the only difference among them was the addition of different sizes of PPF, as shown in Table 2. According to Liang et al. $[23,24]$, the optimum content of the fine PPF and coarse $\mathrm{PPF}$ was $0.9 \mathrm{~kg} \cdot \mathrm{m}^{-3}$ and $6.0 \mathrm{~kg} \cdot \mathrm{m}^{-3}$, respectively.

2.2. Preparation of Specimens. The specimens were poured into two different steel molds, namely, $100 \mathrm{~mm} \times 100 \mathrm{~mm} \times$ $100 \mathrm{~mm}$ and $100 \mathrm{~mm} \times 100 \mathrm{~mm} \times 400 \mathrm{~mm}$, then compacted on a vibrating table, covered by a plastic film, and demolded after $24 \mathrm{~h}$. The specimens were then placed in the standard curing chamber at a temperature of $20 \pm 2^{\circ} \mathrm{C}$ with a relative humidity of more than $95 \%$ for $28 \mathrm{~d}$. The specimens with dimensions $100 \mathrm{~mm} \times 100 \mathrm{~mm} \times 100 \mathrm{~mm}$ were used for the static test, and the specimens with dimensions $100 \mathrm{~mm} \times$ $100 \mathrm{~mm} \times 400 \mathrm{~mm}$ were used for the SHPB test. According to Li and Meng and Wang et al. $[15,25]$, to minimize the inertia effect on the accuracy of the SHPB test, the optimal height-to-diameter ratio of the specimen was in the range of 0.4-0.5. Herein, the specimens with dimensions $\Phi 70 \mathrm{~mm} \times$ $35 \mathrm{~mm}$ were used in this paper, which were fabricated from the prism specimens, as shown in Figure 2. The surface roughness of specimens was less than $0.02 \mathrm{~mm}$ for better contact with bars. Three replicates were conducted for each group to verify the reproducibility of results.

2.3. Static Test. The static test was carried out by using the YAW-1000 pressure tester. During the loading process, the maximum load $P$ was recorded to calculate the compressive strength $f_{c}$. If the difference of the test result exceeds $15 \%$ in one group, one more test was added. Otherwise, the average value was adopted to represent the test result.

2.4. SHPB Test. SHPB test has been widely applied to test the impact response of concrete-like materials. In this study, a $74 \mathrm{~mm}$ various cross-section split-Hopkinson pressure bar testing apparatus was used. It mainly contains several components: pressure bar system, data acquisition system, data processing system, and launch system, as shown in Figure 3. During the SHPB test, strain gauges can acquire the information of the incident wave $\left(\varepsilon_{i}(t)\right)$, reflected wave $\left(\varepsilon_{r}(t)\right)$, and transmitted wave $\left(\varepsilon_{t}(t)\right)$. According to the one-dimensional pulse theory and the hypotheses of plane section and stress uniformity, strain rate $\left(\dot{\varepsilon}_{s}\right)$, strain $\left(\varepsilon_{s}\right)$, and stress $\left(\sigma_{s}\right)$ can be calculated as the following equation:

$$
\left\{\begin{array}{l}
\dot{\varepsilon}_{s}(t)=\frac{C_{0}}{l_{s}}\left[\varepsilon_{i}(t)-\varepsilon_{r}(t)-\varepsilon_{t}(t)\right] \\
\varepsilon_{s}(t)=\frac{C_{0}}{l_{s}} \int_{0}^{t}\left[\varepsilon_{i}(t)-\varepsilon_{r}(t)-\varepsilon_{t}(t)\right] \mathrm{d} \tau \\
\sigma_{s}(t)=\frac{\mathrm{EA}}{2 A_{s}}\left[\varepsilon_{i}(t)+\varepsilon_{r}(t)+\varepsilon_{t}(t)\right]
\end{array}\right.
$$

where $E$ and $A$ are the elastic modulus and cross-section area of the pressure bars, $A_{s}$ and $l_{s}$ are the cross-section area and length of the specimens, respectively, and $C_{0}$ is the longitudinal wave velocity of the pressure bars.

The striker bar impacted the incident bar under the set nitrogen pressures which include $0.3,0.35,0.4,0.45$, and $0.5 \mathrm{MPa}$. It should be noted that the strain rate was the average of the stable section in the strain rate-time curve, which was $28-37 \mathrm{~s}^{-1}$ for $0.3 \mathrm{MPa}, 61-71 \mathrm{~s}^{-1}$ for $0.35 \mathrm{MPa}$, $72-83 \mathrm{~s}^{-1}$ for $0.4 \mathrm{MPa}, 89-96 \mathrm{~s}^{-1}$ for $0.45 \mathrm{MPa}$, and $98-111 \mathrm{~s}^{-1}$ for $0.5 \mathrm{MPa}$ in this paper. To improve the performance of the SHPB device and the reliability of testing data, some measures were taken as follows: (1) pasting 


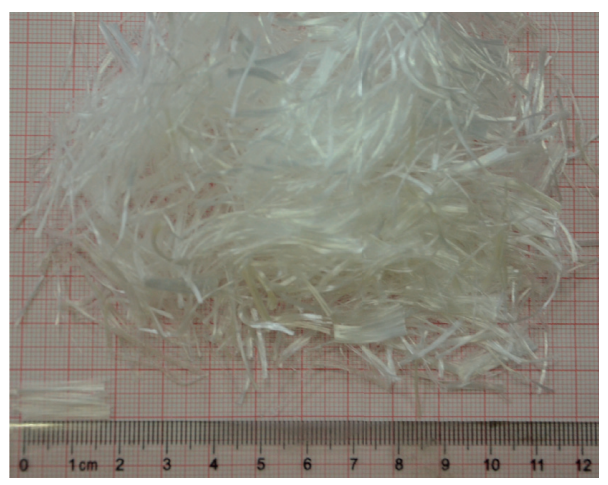

(a)

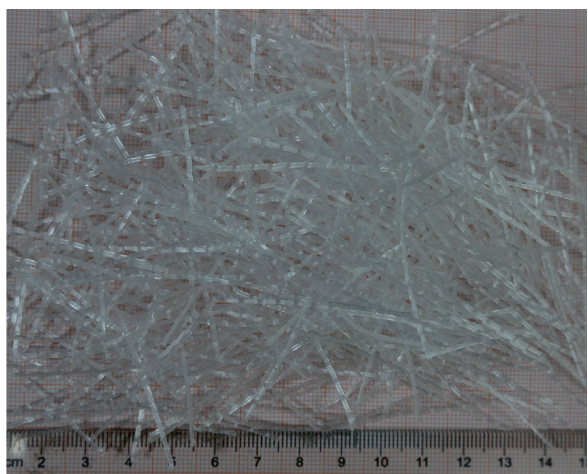

(b)

FIgure 1: Polypropylene fibers: (a) fine PP fiber; (b) coarse PP fiber.

TABLE 1: Physical-mechanical indices of polypropylene fibers.

\begin{tabular}{lccccccc}
\hline $\begin{array}{l}\text { PP } \\
\text { fiber }\end{array}$ & $\begin{array}{c}\text { Diameter } \\
(\mathrm{mm})\end{array}$ & $\begin{array}{c}\text { Length } \\
(\mathrm{mm})\end{array}$ & $\begin{array}{c}\text { Tensile } \\
\text { strength } \\
(\mathrm{MPa})\end{array}$ & $\begin{array}{c}\text { Elastic } \\
\text { modulus } \\
(\mathrm{GPa})\end{array}$ & $\begin{array}{c}\text { Percent } \\
\text { elongation }\end{array}$ & $\begin{array}{c}\text { Density } \\
\left(\mathrm{kg} / \mathrm{m}^{3}\right)\end{array}$ & $\begin{array}{c}\text { Recommended } \\
\text { content } \\
\left.\mathrm{m}^{3}\right)\end{array}$ \\
\hline $\begin{array}{l}\text { Fine PP } \\
\text { Coarse }\end{array}$ & 0.026 & 19 & 641 & 4.5 & 40 & 910 & 0.9 \\
PP & 0.8 & 50 & 706 & 7.4 & 10 & 950 & 6.0 \\
\hline
\end{tabular}

TABLE 2: Mixture proportion $\left(\mathrm{kg} / \mathrm{m}^{3}\right)$.

\begin{tabular}{lccccccccc}
\hline Specimen no. & Fiber type & Fiber content & Cement & Sand & Detritus & Water & Water/cement & Sand ratio & Water reducer \\
\hline A1 & --- & 0 & 380 & 701 & 1144 & 175 & 0.46 & $38 \%$ & 3.8 \\
A2 & Fine PPF & 0.9 & 380 & 701 & 1144 & 175 & 0.46 & $38 \%$ & 3.8 \\
A3 & Coarse PPF & 6.0 & 380 & 701 & 1144 & 175 & 0.46 & $38 \%$ & 3.8 \\
A4 & Hybridization & $0.6+5.4$ & 380 & 701 & 1144 & 175 & 0.46 & $38 \%$ & 3.8 \\
A5 & Hybridization & $0.9+5.1$ & 380 & 701 & 1144 & 175 & 0.46 & $38 \%$ & 3.8 \\
A6 & Hybridization & $1.2+4.8$ & 380 & 701 & 1144 & 175 & 0.46 & $38 \%$ & 3.8 \\
\hline
\end{tabular}

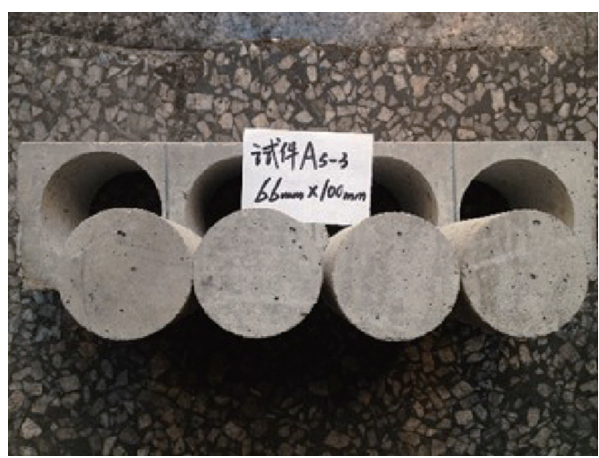

(a)

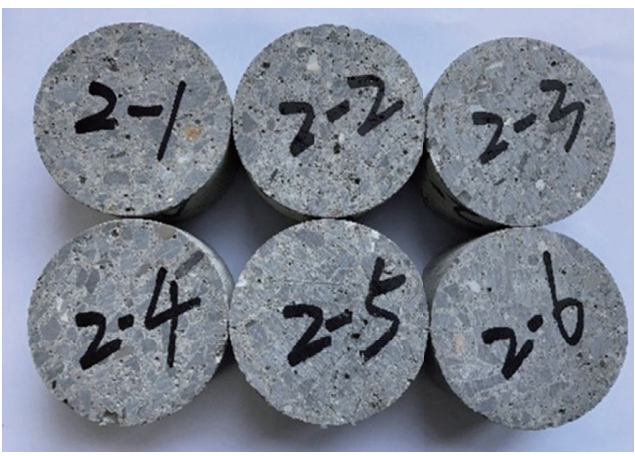

(b)

FIGURE 2: Specimens for SHPB tests: (a) after coring; (b) after cutting and grinding.

rubber shaper sheet [26] between the bullet and the incident bar to extend the rising edge of the incident pulse and eliminate the waveform oscillation to smooth the waveform;
(2) painting the ends of specimens with petroleum jelly [27] to minimize the friction between specimens and pressure bars and ensure stress uniformity. 


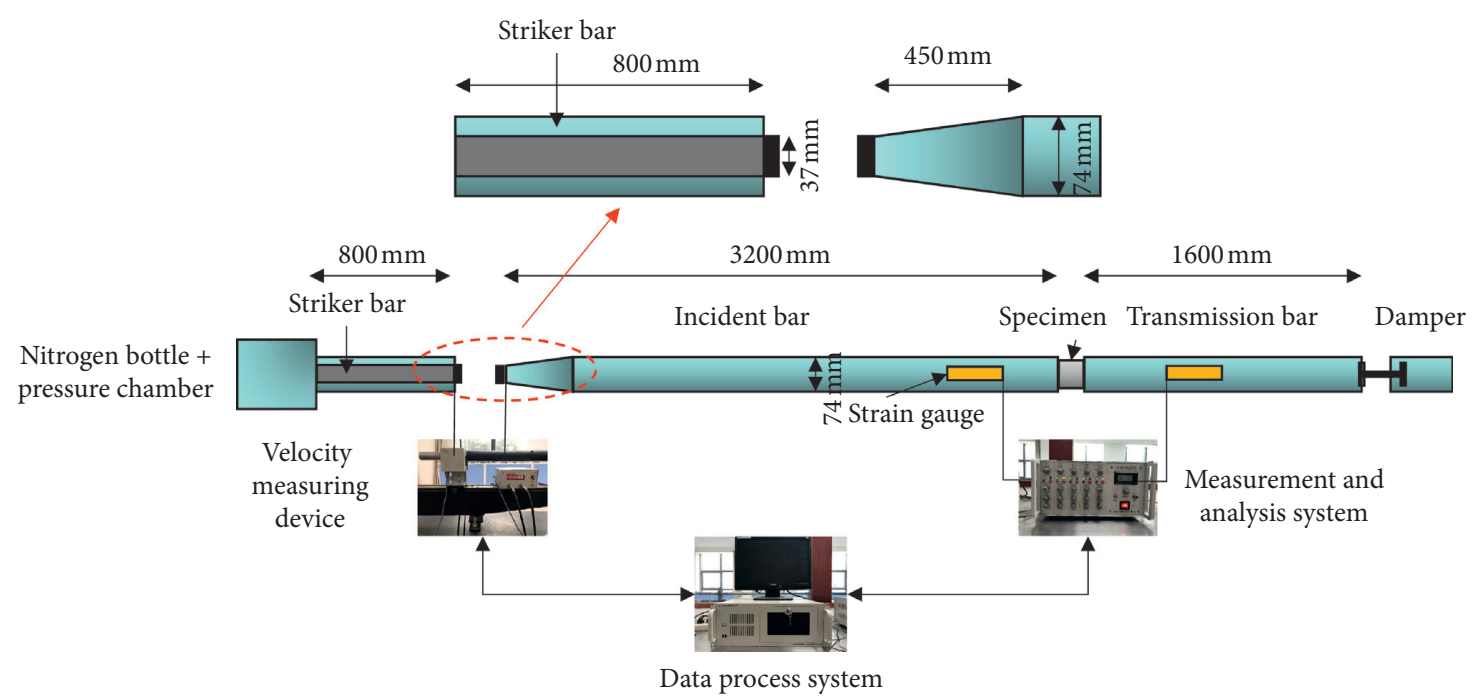

Figure 3: Schematic illustration of the SHPB apparatus.

\section{Results and Discussion}

3.1. Static Test Result. The static compressive strength of all groups is shown in Figure 4. It showed a clear result that the hybrid polypropylene fibers can significantly affect the compressive strength of concrete, and the effect of the coarse PPF was dominant. The compressive strength of three groups of HPFRC (A4, A5, and A6) was higher than the concrete reinforced with one size of PPF (A2 and A3); it demonstrated that the workability of HPFRC is better than concrete reinforced with one kind of fiber. Group A6 had the maximum static compressive strength, which increased by $33.4 \%$, compared with the conventional concrete (A1). It can also be observed that the reinforcement effect of fine-coarse PPFs was not weakened along with the increase in the mix proportion of fine PPF, while the tendency of improvement becomes slow. Herein, it can be predicted that the optimal quality mix proportion of fine-coarse PPFs is around 0.2. Besides, the static compressive strength influence factor $S_{f}=f_{c} / f_{c}^{\prime}$ was introduced in this paper, where $f_{c}$ is the compressive strength of PPF-reinforced concrete and $f_{c}^{\prime}$ is the compressive strength of conventional concrete. The results of $S_{f}$ are shown in Table 3.

Both fine PPF and coarse PPF play the role of bridging and reinforcing, and the degree of stress concentration will be alleviated, and the stress inside the concrete tends to be more uniform. On the contrary, different kinds of PPF can play different roles in different phases. Fine PPF restrained the initial microcracks, and then the coarse PPF began to sustain the load with the microcracks propagated further [28]. Meanwhile, there exists an optimal mix proportion of PPF; too much fine PPF would produce a negative hybrid effect on properties of HPFRC.

\subsection{SHPB Test Result}

3.2.1. Dynamic Stress-Strain Curves. Dynamic stress-strain curves of HPFRC subjected to different strain rates are displayed in Figure 5. It can be observed from Figure 5 that

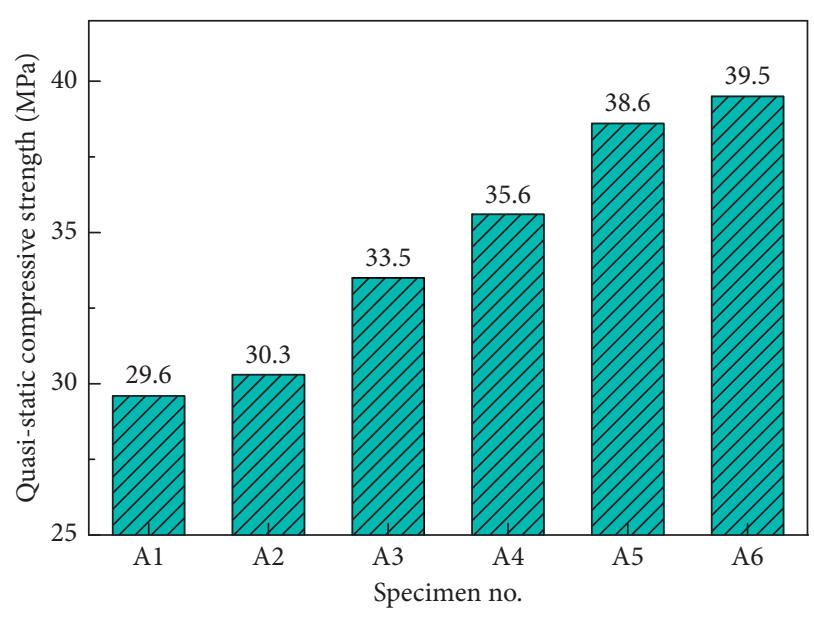

FiguRE 4: Static compressive strength of HPFRC.

TABLE 3: Influence factor $\mathrm{S}_{f}$ of static compressive strength.

\begin{tabular}{lcccc}
\hline Label & A3 & A4 & A5 & A6 \\
\hline$S_{f}$ & 1.132 & 1.202 & 1.304 & 1.334 \\
Fitting value & 1.123 & 1.230 & 1.283 & 1.336 \\
\hline
\end{tabular}

there was a similar trend for dynamic strain-stress curves of all groups with strain rate increased. It has a strengthening effect and a phenomenon of strain softening. Meanwhile, different mixed proportions of PPFs also have a certain effect on the impact response of HPFRC, such as dynamic compressive strength. In this paper, the dynamic compressive strength is the peak stress of the stress-strain curve, and the strain at the peak stress was defined as the peak strain. The DCF is the ratio of dynamic compressive strength to static compressive strength, which reflects the increase of compressive strength of concrete under the impact load and is often used to characterize the effect of strain rates on concrete-like materials [29]. The impact toughness (IT) is 


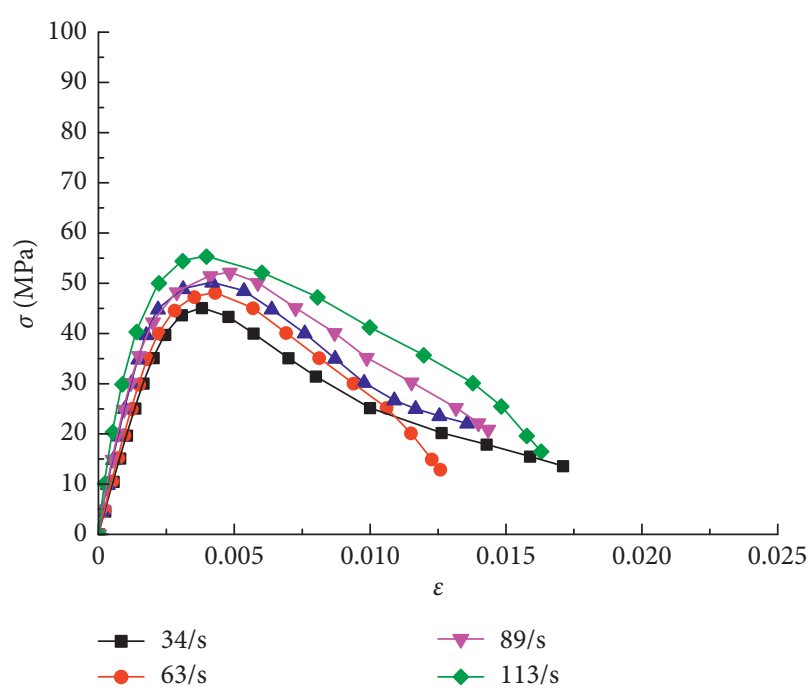

(a)

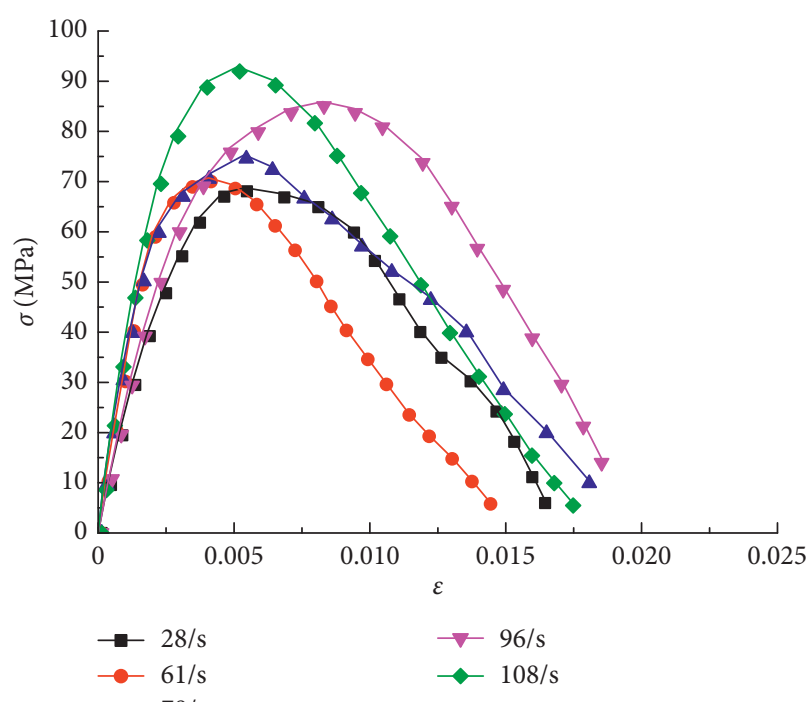

(c)

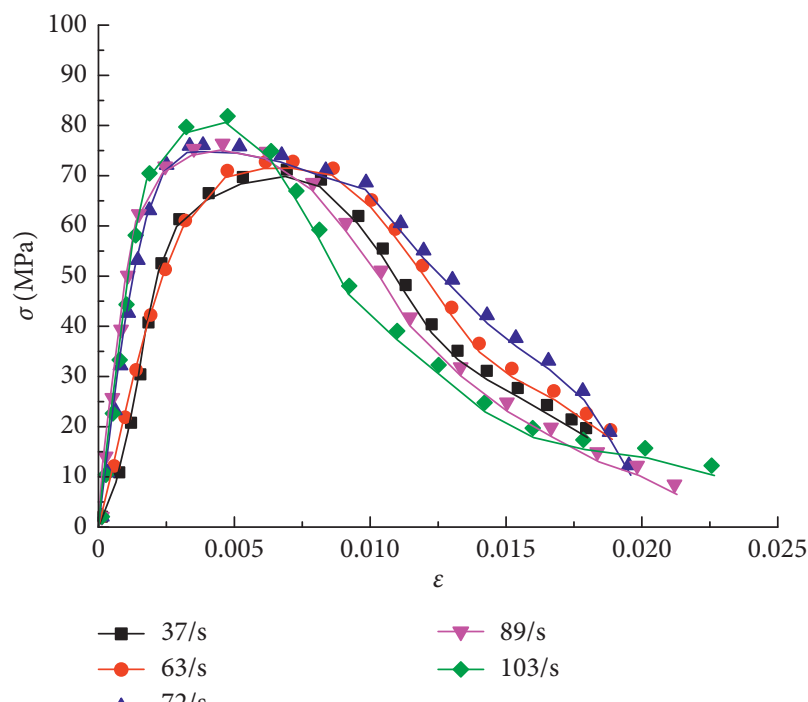

(e)

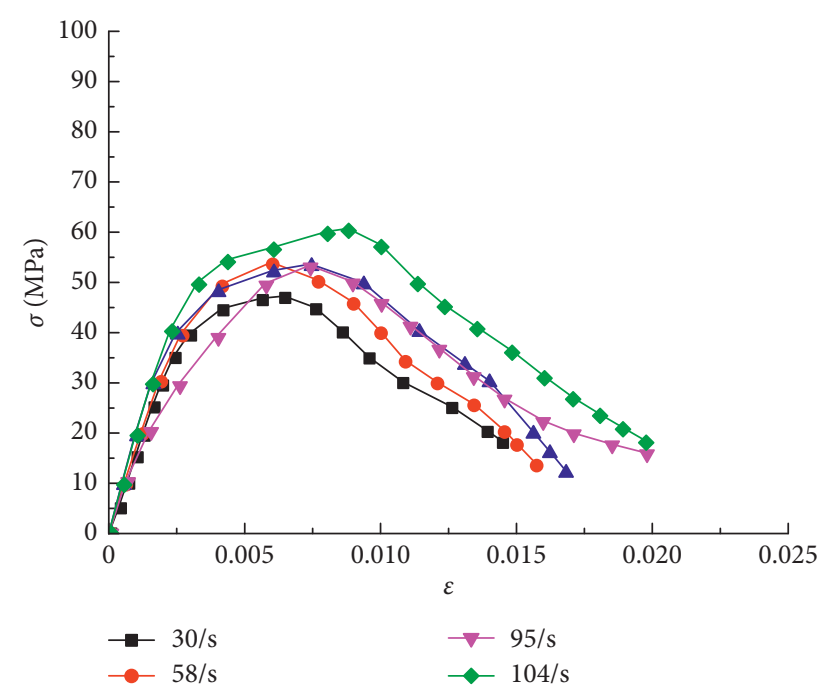

(b)

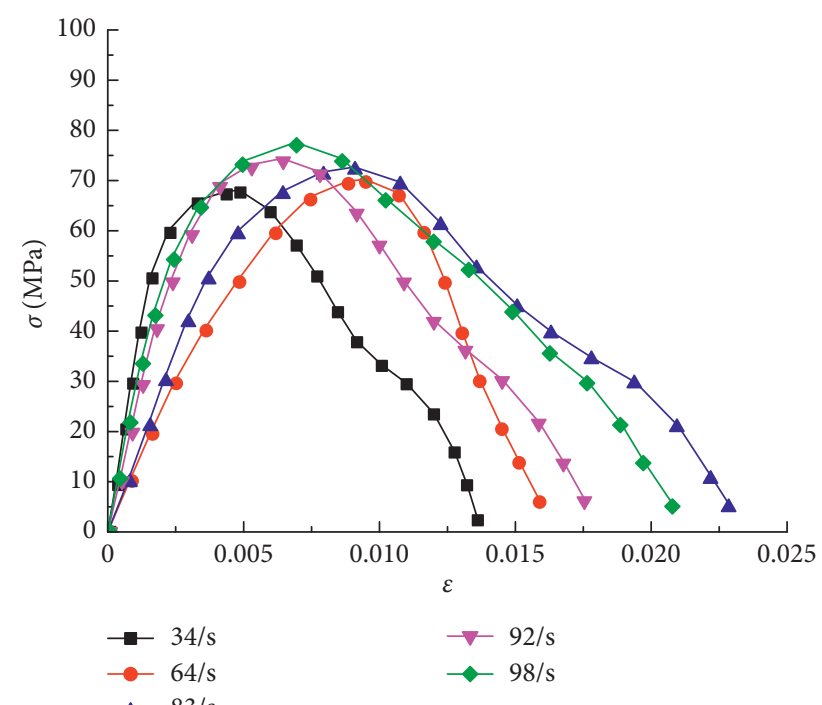

(d)

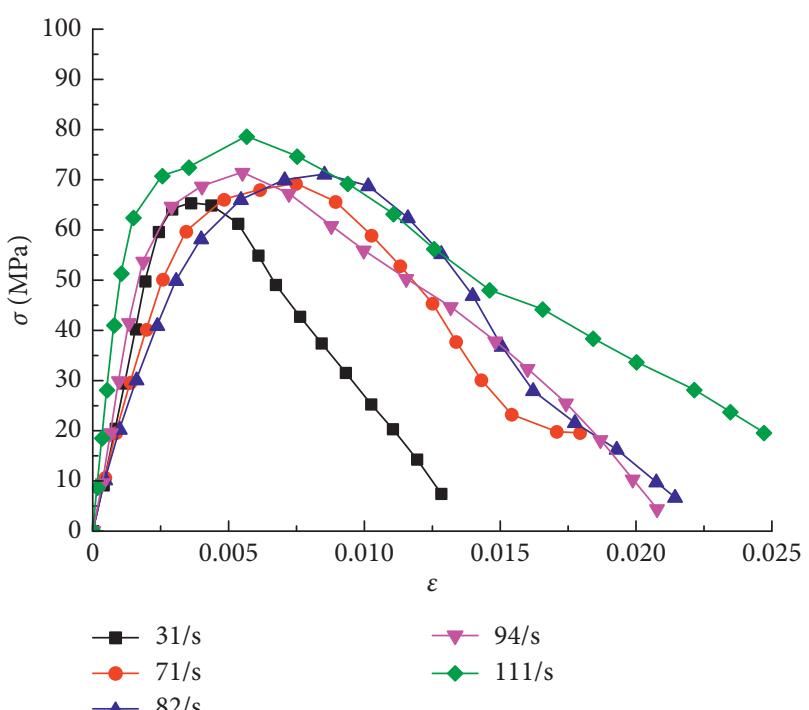

(f)

FIGURe 5: Dynamic stress-strain curves of HPFRC under different strain rates: (a) A1, (b) A2, (c) A3, (d) A4, (e) A5, and (f) A6. 
equal to the energy absorbed by the specimen from loading. $\mathrm{IT}_{P}$ considered here was the integration of the stress-strain curve before peak strain, and IT $_{\text {MAX }}$ considered here was obtained by integrating the stress-strain curve up to the ultimate strain. The dynamic characteristic parameters are tabulated in Table 4.

3.2.2. Effect of Strain Rate. Figure 6 depicts the variation rule of characteristic dynamic parameters of HPFRC under different strain rates. Figure 6(a) gives the relationship between the dynamic compressive strength and the strain rate. It can be observed that the dynamic compressive strength of all groups of specimens increased with increase in the strain rate. From the perspective of energy absorption, the time of the impact load acted on the specimens was shorter as the strain rate increased. There was no enough time for the growth and propagation of the internal microcrack. Hence, the internal stress of specimens increased to balance the external input energy. Meanwhile, it can be observed that proper hybrid fine-coarse PPF has a significant improvement in the dynamic compressive strength of concrete. When the impact load was $0.3 \mathrm{MPa}$ and $0.5 \mathrm{MPa}$, the dynamic compressive strength of $\mathrm{A} 5$, respectively, increased by $54.78 \%$ and $45.43 \%$ compared with $\mathrm{A} 1$, as shown in Figure 6(b).

Figure 6(c) shows the relationship and fitted line between the DCF and the decimal logarithm of strain rate (lg $\dot{\varepsilon})$. It can be seen that there is an approximately linear relationship between them. Herein, the following equation is used to describe the relationship between the DCF for HPFRC and the strain rate:

$$
\mathrm{DCF}=m \lg \dot{\varepsilon}+n,
$$

where $m$ and $n$ are the correlation coefficients and are related to the fiber content. Besides, $m$ is related to strain-rate effect coefficients.

Table 5 lists the results of the fitted DCF function; $R^{2}$ is the coefficient of determination between the test and the fitted results, which reflects the quality of fitted results, and $R^{2}$ close to 1 means a good fitted result. From the fitted result, it indicates the fitted results can well describe the relationship between DCF and $\lg \dot{\varepsilon}$. The inhomogeneity of HPFRC and dispersion effect may result in the deviation of several data. Besides, the transversely distributed fine and coarse PPFs increase the transverse inertial effect. From Figures 6(a) 6(c) and Table 5, it can be concluded that the addition of fine-coarse PPF enhance the strain rate effect of the dynamic compressive strength of concrete. As a result, the strain rate effect of the dynamic compressive strength of HPFRC was better than that of conventional concrete. Meanwhile, it can be found that the coarse PPF plays an important role in the enhancement effect.

The peak strain and ultimate strain are significant indices for assessing the deformation capacity of concrete. For the peak strain of HPFRC, they were higher than the conventional concrete at the same strain rate. As regards the ultimate strain, there was an obvious phenomenon of strain rate hardening. It rose when the strain rate increased in general. Hence, the failure of HPFRC subjected to the impact load was determined by both strain rate hardening and strain softening. Meanwhile, it can be found that although the variation rule of axial strain at high strain rate was certain volatility and uncertainty, the tendency of increment can be seen with strain rate increased, and groups of HPFRC performed better than groups $\mathrm{A} 1 \sim \mathrm{A} 3$. Impact toughness is an essential index for assessing energy absorption capacity and ductility of concrete. The calculated results for peak toughness $\mathrm{IT}_{P}$ and ultimate toughness $\mathrm{IT}_{\text {MAX }}$ are shown in Table 4 and plotted in Figure 6(e). It can be seen that the ultimate toughness of specimens showed a significant strain rate effect and fiber strengthening effect. On the one hand, the time of higher impact load acted on the specimen was shorter, and more energy was required for the generation of a crack than the propagation of a crack; this caused newer cracks generated to consume more energy. On the other hand, as per the fiber spacing theory [30], a stress field would be generated to restrain crack growth and propagation when the crack propagates to the interface between the concrete matrix and fibers. This stress field alleviates the stress concentration on the tip of cracks. Meanwhile, different sizes of PPF can be effective in arresting cracks at both micro- and macrolevels. Herein, the ultimate toughness and dynamic compressive strength of HPFRC increased.

3.2.3. Effect of the Hybrid Fine-Coarse PPF. As previously stated, the hybridization of the fine and coarse PPF can result in better performance synergy, including the static strength, the dynamic compressive strength, and the ultimate toughness. To compare the effect of four different hybridizations of the fine-coarse PPF, A3, A4, A5, and A6 were chosen as the objects to analyze. The quality proportion of the fine PPF for four groups of specimens was $0 \%, 10 \%, 15 \%$, and $20 \%$, respectively, and the total PPF content was $6 \mathrm{~kg} / \mathrm{m}^{3}$ to guarantee the comparability of the test results. Figure 7 gives a comparison of dynamic properties between different fiber hybridizations. Figure 7 (a) presents the relationship between the hybrid polypropylene fiber and the dynamic compressive strength. It showed that all the hybrid fibers in the range of tests were not very sensitive for dynamic compressive strength. They were at a close level (the deviation of serval data may be caused by the dispersion of test data), but at a lower strain rate, the dynamic compressive strength of group A5 was higher. Too much fine PPF will cause a negative hybrid effect. Besides, it indicates that the strain rate has an effect on the synergy workability of two fibers. Too high strain rates may pullout fibers and reduce the effect of fibers. From the overall tendency, A3 and A5 had better performance than A4 and A6. Figures 7(b) and $7(\mathrm{c})$, respectively, present the comparison of peak strain and ultimate stain, $\mathrm{IT}_{P}$ and $\mathrm{IT}_{\mathrm{MAX}}$, for different fiber hybridizations at various impact loads. It can be seen that the relationship between them was not obvious and a little discrete. This may be caused by the inconsistency of strain rate under the same impact load and the nonuniform distribution of two sizes of PPFs. From the overall analysis, the proper hybridization would improve the toughness of 
TABLE 4: The dynamic characteristic parameters of HPFRC in the SHPB test.

\begin{tabular}{|c|c|c|c|c|c|c|c|c|}
\hline $\begin{array}{l}\text { Specimen } \\
\text { no. }\end{array}$ & $\begin{array}{c}\text { Impact load } \\
(\mathrm{MPa})\end{array}$ & $\begin{array}{l}\text { Strain rate } \\
\left(\mathrm{s}^{-1}\right)\end{array}$ & $\begin{array}{c}\text { Compressive strength } \\
(\mathrm{MPa})\end{array}$ & DCF & $\begin{array}{c}\text { Peak strain } \\
\left(10^{-3}\right)\end{array}$ & $\begin{array}{l}\text { Ultimate strain } \\
\left(10^{-3}\right)\end{array}$ & $\begin{array}{c}\mathrm{IT}_{P} \\
\left(\mathrm{~kJ} \cdot \mathrm{m}^{-3}\right)\end{array}$ & $\begin{array}{r}\mathrm{IT}_{\text {MAX }} \\
\left(\mathrm{kJ} \cdot \mathrm{m}^{-3}\right)\end{array}$ \\
\hline \multirow{5}{*}{ A1 } & 0.3 & 34 & 45.13 & 1.525 & 3.790 & 17.11 & 112.1 & 468.8 \\
\hline & 0.35 & 63 & 48.20 & 1.628 & 4.276 & 12.58 & 143.2 & 419.7 \\
\hline & 0.4 & 74 & 50.20 & 1.696 & 4.173 & 13.57 & 153.3 & 484.1 \\
\hline & 0.45 & 89 & 52.23 & 1.765 & 4.824 & 14.35 & 188.1 & 540.3 \\
\hline & 0.5 & 113 & 55.42 & 1.872 & 3.959 & 16.30 & 163.9 & 657.5 \\
\hline \multirow{5}{*}{ A2 } & 0.3 & 30 & 47.27 & 1.560 & 6.445 & 14.52 & 222.0 & 486.4 \\
\hline & 0.35 & 58 & 54.02 & 1.783 & 5.982 & 15.77 & 219.2 & 571.1 \\
\hline & 0.4 & 83 & 53.65 & 1.771 & 7.424 & 16.86 & 300 & 646.0 \\
\hline & 0.45 & 95 & 53.40 & 1.762 & 7.386 & 19.86 & 255.9 & 661.7 \\
\hline & 0.5 & 104 & 60.75 & 2.005 & 8.801 & 19.83 & 408.6 & 834.9 \\
\hline \multirow{5}{*}{ A3 } & 0.3 & 28 & 68.78 & 2.053 & 5.405 & 16.49 & 251.2 & 758.9 \\
\hline & 0.35 & 61 & 70.72 & 2.111 & 4.067 & 14.46 & 205.1 & 622.6 \\
\hline & 0.4 & 78 & 75.32 & 2.248 & 5.383 & 18.13 & 302.9 & 891.6 \\
\hline & 0.45 & 96 & 85.91 & 2.564 & 8.268 & 18.59 & 516.8 & 1121.1 \\
\hline & 0.5 & 108 & 92.9 & 2.773 & 5.132 & 17.53 & 339.8 & 999.2 \\
\hline \multirow{5}{*}{ A4 } & 0.3 & 34 & 68.13 & 1.914 & 4.824 & 13.61 & 248.9 & 605.9 \\
\hline & 0.35 & 64 & 70.25 & 1.973 & 9.476 & 15.90 & 429.4 & 710.9 \\
\hline & 0.4 & 83 & 72.69 & 2.042 & 9.076 & 22.95 & 450.0 & 1047.1 \\
\hline & 0.45 & 92 & 74.38 & 2.089 & 6.411 & 17.54 & 337.6 & 832.8 \\
\hline & 0.5 & 98 & 77.6 & 2.180 & 6.905 & 20.82 & 389.8 & 1051.3 \\
\hline \multirow{5}{*}{ A5 } & 0.3 & 37 & 69.85 & 1.810 & 6.871 & 18.03 & 351.8 & 820.2 \\
\hline & 0.35 & 63 & 71.50 & 1.852 & 7.103 & 19.02 & 375.6 & 904.2 \\
\hline & 0.4 & 72 & 74.78 & 1.937 & 3.760 & 19.59 & 204.5 & 1026.1 \\
\hline & 0.45 & 89 & 75.09 & 1.945 & 4.486 & 21.31 & 267.9 & 912.6 \\
\hline & 0.5 & 103 & 80.60 & 2.088 & 4.670 & 22.70 & 293.2 & 895.8 \\
\hline \multirow{5}{*}{ A6 } & 0.3 & 31 & 65.43 & 1.656 & 3.607 & 12.76 & 147.5 & 509.2 \\
\hline & 0.35 & 71 & 69.28 & 1.754 & 7.475 & 17.96 & 385.1 & 837.0 \\
\hline & 0.4 & 82 & 71.11 & 1.800 & 8.522 & 21.48 & 438.9 & 954.6 \\
\hline & 0.45 & 94 & 71.49 & 1.810 & 5.498 & 20.77 & 293.2 & 946.2 \\
\hline & 0.5 & 111 & 80.60 & 2.041 & 4.670 & 24.73 & 355.0 & 1290.8 \\
\hline
\end{tabular}

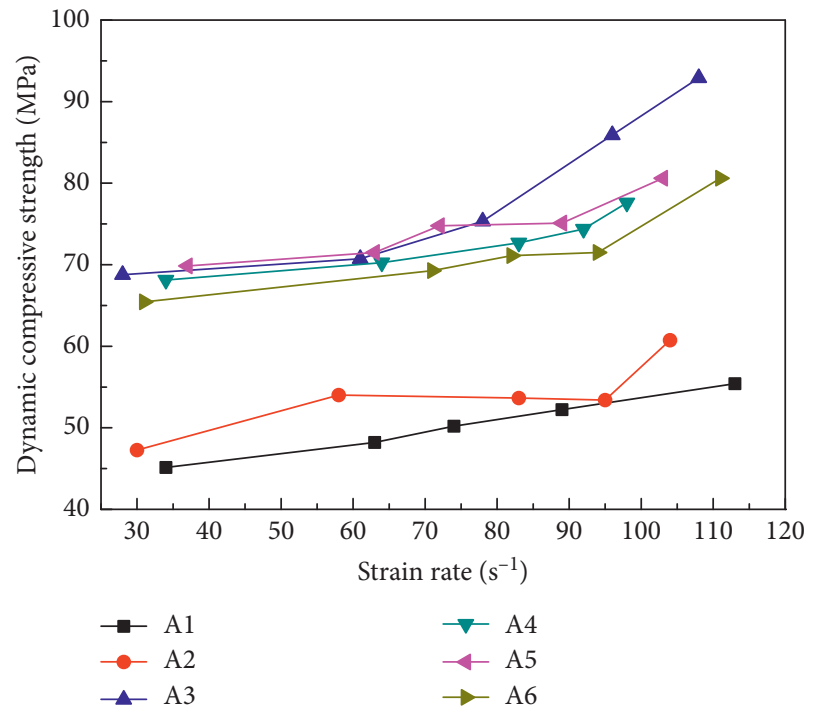

(a)

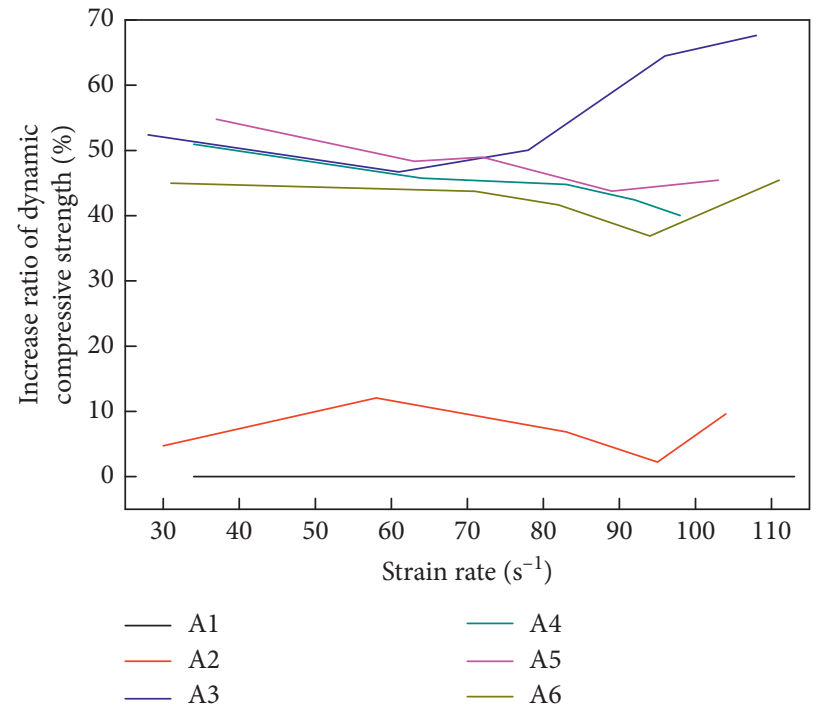

(b)

FIGURE 6: Continued. 


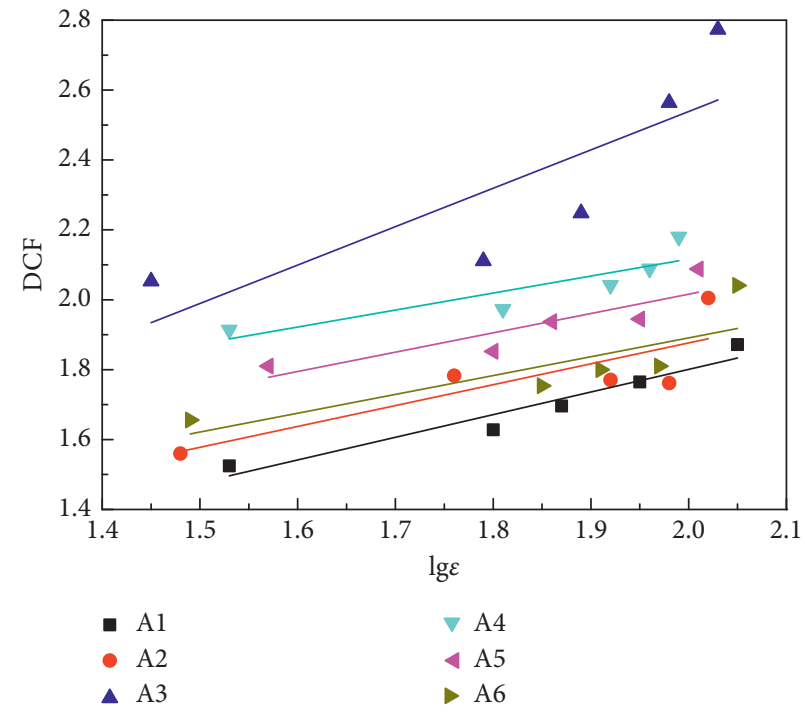

(c)

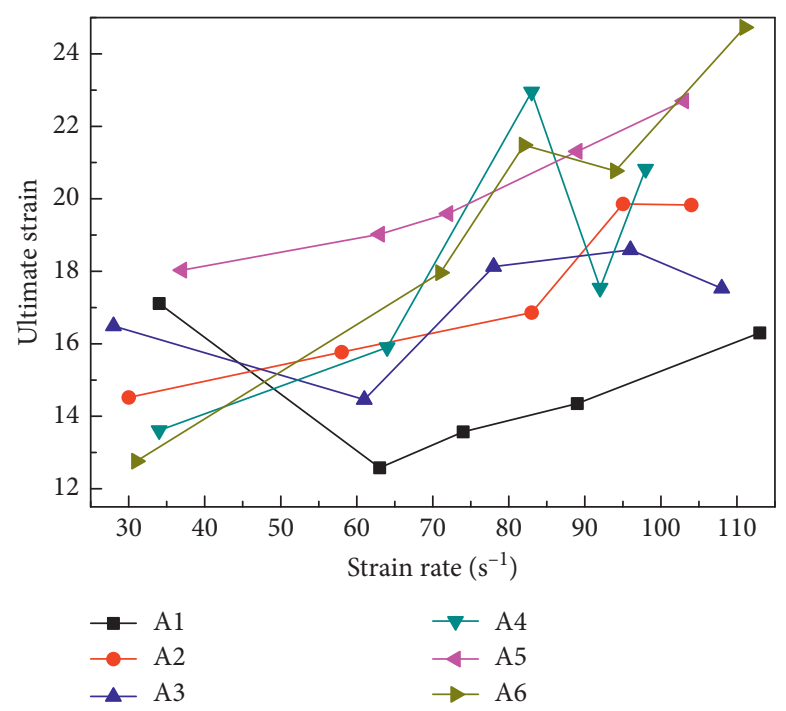

(d)

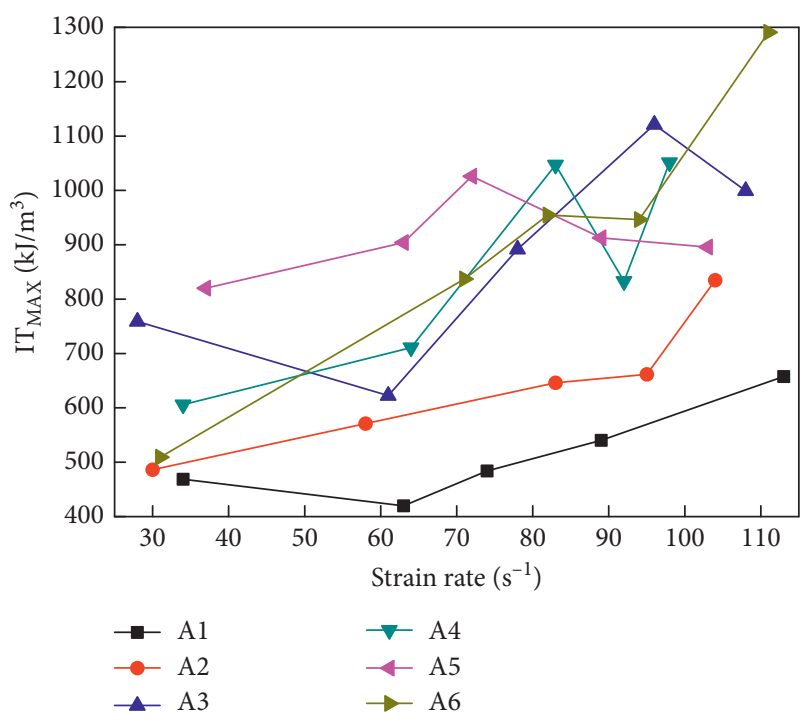

(e)

FIGURE 6: Strain rate effect on characteristic dynamic parameters of concrete: (a) on the peak stress, (b) on the increase ratio of peak stress, (c) on the DCF, (d) on the ultimate strain, and (e) on impact toughness IT $_{\text {MAX. }}$.

TABLE 5: Fitted DCF functions.

\begin{tabular}{lcccrr}
\hline Specimen no. & Coarse content $\left(\mathrm{kg} / \mathrm{m}^{3}\right)$ & Fine content $\left(\mathrm{kg} / \mathrm{m}^{3}\right)$ & Functions & $R$ \\
\hline A1 & 0 & 0 & DCF $=0.648 \lg \dot{\varepsilon}+0.505$ & 0.954 & 0.911 \\
A2 & 0 & 0.9 & DCF $=0.681 \lg \dot{\varepsilon}+0.598$ & 0.775 & 0.601 \\
A3 & 6 & 0 & DCF $=1.099 \lg \dot{\varepsilon}+0.342$ & 0.751 \\
A4 & 5.4 & 0.6 & DCF $=0.486 \lg \dot{\varepsilon}+1.145$ & 0.841 & 0.564 \\
A5 & 5.1 & 0.9 & DCF $=0.553 \lg \dot{\varepsilon}+0.909$ & 0.838 & 0.707 \\
A6 & 4.8 & 1.2 & DCF $=0.539 \lg \dot{\varepsilon}+0.814$ & 0.755 & 0.670 \\
\hline
\end{tabular}

concrete compared with A3, blending with one size of PPF; it indicates that there exists an optimal hybrid proportion for the HPFRC. Hybrid fine-coarse PPFs work in different crack propagation stages to improve concrete workability. Fine fiber plays an important role in inhibiting the propagation of microcracks. Fine PPF can arrest microcracks caused by plastic shrinkage and temperature deformation and can reduce the stress concentration at the tip of initial cracks or initial loading stage. While the coarse fiber inhibits the propagation of macrocracks, the coarse PPF can fully play 


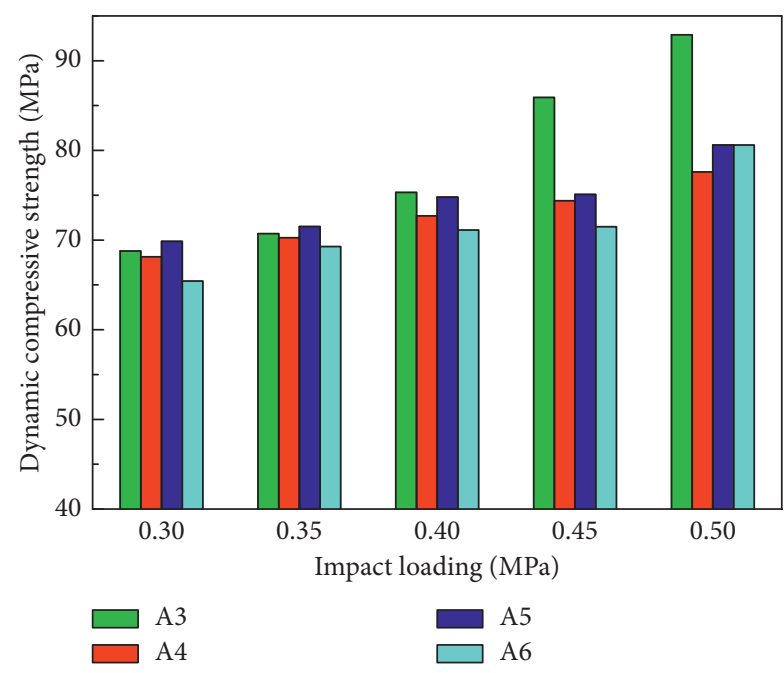

(a)

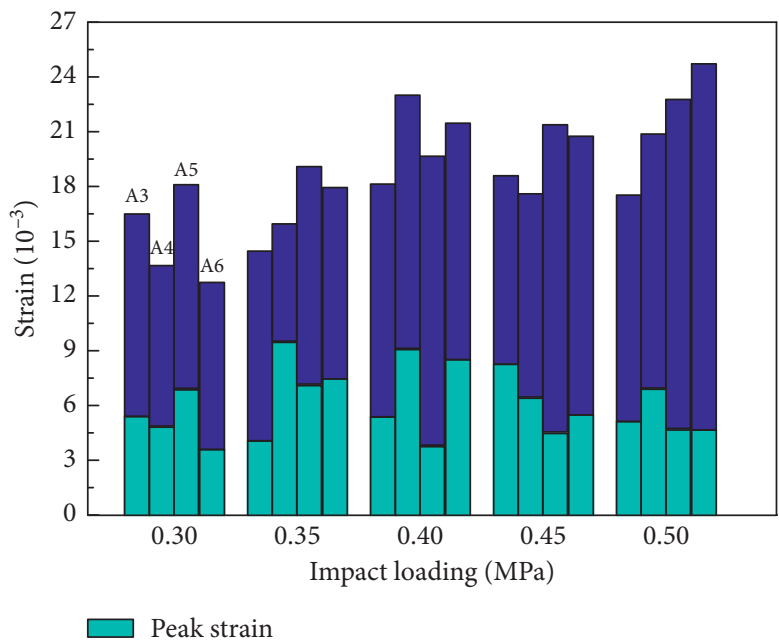

Peak strain

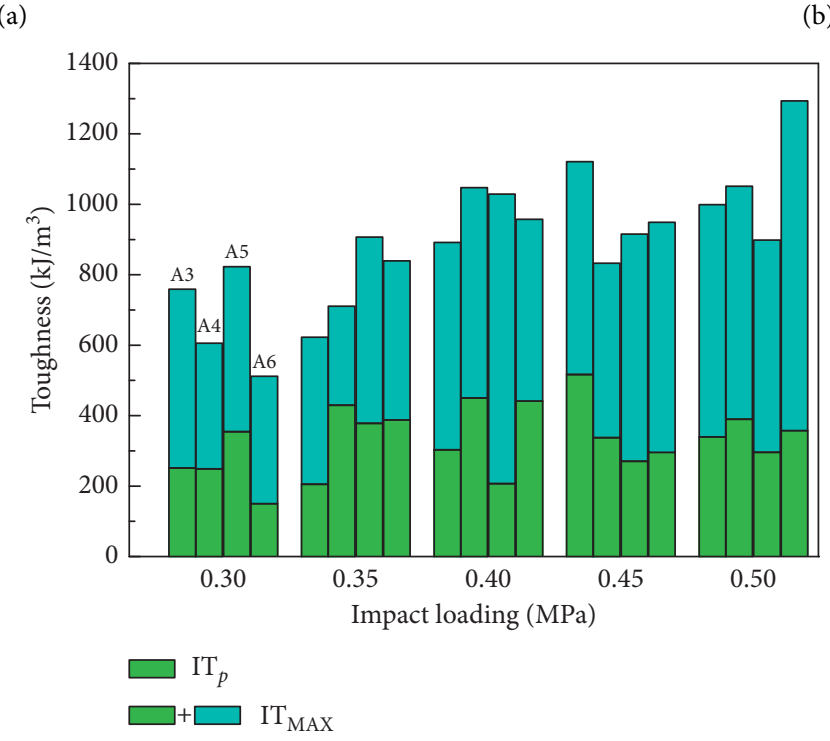

(b)

(c)

Figure 7: Comparison of dynamic properties between different fiber hybridizations: (a) on dynamic compressive strength, (b) on peak strain and ultimate strain, and (c) on $\mathrm{IT}_{P}$ and $\mathrm{IT}_{\mathrm{MAX}}$.

the bridging role, limiting the relative displacement and deformation of the concrete on both sides of the crack. The bridging effect of the hybrid fine-coarse PPF is more conducive to enhancing the deformation capacity of concrete, and Figure 8 gives the failure pattern of specimens.

From Figure 4, it can be seen that the static compressive strength of HPFRC increases with the increasing quality proportion of fine PPFs in the range of the test. That is, the proportion of the hybrid fine-coarse PPFs has a certain effect on the static compressive strength. So, the characteristic parameter of PPF, $k \lambda$, was introduced to characterize the effect of the fiber, where $k$ is the lengthdiameter ratio of the fiber itself and $\lambda$ is the fiber content of HPFRC. Hence, the characteristic parameter of the coarse fiber is $k_{c} \lambda_{c}$, and the characteristic parameter of the fine fiber is $k_{f} \lambda_{f}$. According to the theory of composite material, equation (3) is obtained in the following to express the relationship between $S_{f}$ and characteristic parameters:

$$
\begin{aligned}
S_{f} & =\frac{f_{c}}{f_{c}^{\prime}}=\alpha_{f} k_{f} \lambda_{f}+\alpha_{c} k_{c} \lambda_{c}, \\
\lambda_{f}+\lambda_{c} & =1, \\
\lambda_{f} & =\frac{m_{f}}{m_{f}+m_{c}}, \\
\lambda_{c} & =\frac{m_{c}}{m_{f}+m_{c}}, \\
S_{f} & =\left(\alpha_{f} k_{f}-\alpha_{c} k_{c}\right) \lambda_{f}+\alpha_{c} k_{c},
\end{aligned}
$$

where $\alpha_{f}$ and $\alpha_{c}$ are correlation coefficients and are related to the fiber itself. $\lambda_{f}$ is the fine PPF content proportion. 


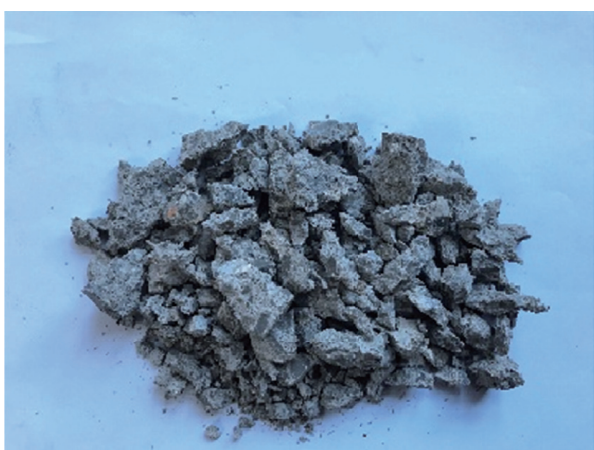

(a)

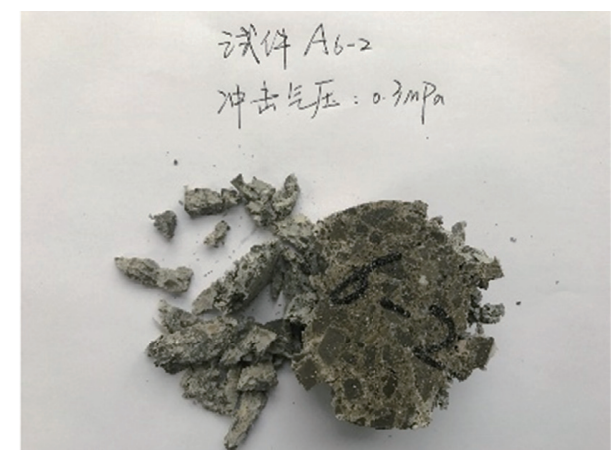

(b)

Figure 8: The failure pattern of specimens under 0.3 MPa: (a) A1; (b) A6.

$m_{f}$ and $m_{c}$ are quality content of the fine and coarse PPF, respectively. Figure 9 depicts the relationship between them and the fitting curve of the test data. It indicates that their relationship is approximately linear in the range of the test content. According to the fitting result, Table 3 gives a comparison between the fitting value and the influence factor. $\alpha_{f} \approx 0.003, \alpha_{c} \approx 0.018$, and $R^{2}$ is 0.928 , which means the fitting result can well describe the test result.

\section{Constitutive Model and Numerical Calculation}

4.1. HJC Constitutive Model. The HJC model was originally proposed for impact computations of concrete-like materials subjected to large strains, high strain rates, and high pressures. The state equation is shown as follows:

$$
\sigma^{*}=\left[A(1-D)+\mathrm{BP}^{* N}\right]\left(1+C \lg \left(\dot{\varepsilon}^{*}\right)\right) \leq S_{\mathrm{MAX}},
$$

where $\sigma^{*}=\sigma / f_{C}^{\prime}, \sigma$ is the actual equivalent stress, $f_{C}^{\prime}$ is the static compressive strength of conventional concrete, $A$ is the normalized cohesive strength, $D$ is the damage factor $(0 \leq D \leq 1.0)$, $\mathrm{B}$ is the normalized pressure hardening coefficient, $P^{*}$ is the dimensionless hydrostatic pressure ( $P^{*}=P / f_{C}^{\prime}, P$ is the actual pressure), $N$ is the pressure hardening exponent, $C$ is the strain rate coefficient, $S_{\text {MAX }}$ is the normalized maximum strength that can be developed, and $A, B, N, C$, and $S_{\mathrm{MAX}}$ are material constants.

As regards fiber concrete specimens, $\sigma_{F}^{*}=\sigma / f_{c}$, and it can be written as equation (7) in the following; and the influence factor has been introduced into the HJC constitutive model to characterize the effect of the polypropylene fiber on the static strength.

$$
\sigma_{F}^{*}=\frac{\sigma}{f_{c}^{\prime}} \times \frac{f_{c}^{\prime}}{f_{c}}=\sigma^{*} \times \frac{1}{S_{f}} .
$$

4.2. Damage Factor. The mesostructure of concrete-like materials is supposed to be heterogeneous and complex, with different initial microcracks and voids inside. Besides, the addition of two sizes of PPFs aggravates the heterogeneity and complexity of concrete. Thus, the damage evolution of the

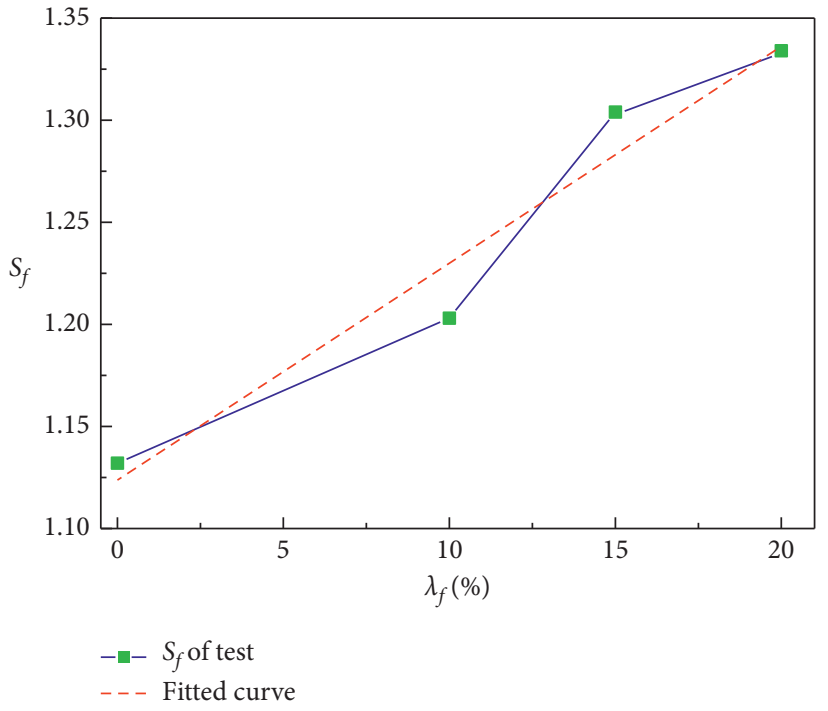

FIGURE 9: Relationship between the proportion of the fine fiber and $S_{f}$

concrete failure process is random. So, the damage factor $D$ in the HJC constitutive model has been modified through the perspective of probability, and $f(\varepsilon)$ is defined as the probability function of the microdestruction of HPFRC, which is related to strain. The relationship between damage factor $D$, strain, and probability is given by the following equation:

$$
\frac{\mathrm{d} D}{\mathrm{~d} \varepsilon}=f(\varepsilon) .
$$

The three-parameter Weibull distribution is widely used to describe failure in normal testing and reliability theory [31]. In this paper, the three-parameter Weibull distribution was used to characterize the damage evolution of HPFRC subjected to the impact load. The corresponding probability density distribution function of the three-parameter Weibull distribution is given by the following equation:

$$
f(x)=\frac{k}{\lambda}\left(\frac{x-\xi}{\lambda}\right)^{k-1} \exp \left[-\left(\frac{x-\xi}{\lambda}\right)^{k}\right],
$$

where $x$ is the random variable, $k(>0)$ is the shape parameter, $\lambda(>0)$ is the scale parameter, and $\xi(>0)$ is the 
location parameter or the threshold $(x \geq \xi)$. Consider the influence of the irreversible deformation and the damage factor $D$ of the HPFRC was zero before the strain reached the threshold, and $D$ can be defined as the following equation:

$$
D= \begin{cases}0, & \varepsilon \leq \varepsilon_{\mathrm{th}}, \\ 1-\exp \left[-\left(\frac{\varepsilon-\varepsilon_{\mathrm{th}}}{a}\right)^{b}\right], & \varepsilon>\varepsilon_{\mathrm{th}},\end{cases}
$$

where $a$ and $b$ are the material constants, which are related to the strain rate, the proportion of fine and coarse PPFs, aspect ratio, and the strength of conventional concrete. $\varepsilon_{\text {th }}$ is the threshold strain of HPFRC material cumulative damage, and it was usually suggested $\varepsilon_{\text {th }}=0.7 \varepsilon_{b} ; \varepsilon_{b}$ is the peak strain. $D=0$ presented that there was no damage existing inside the HPFRC, and the material was in the elastic stage. $D=1$ indicates the HPFRC has been destroyed and completely loses its bearing capacity. Hence, before $\varepsilon_{\text {th }}$, the HPFRC did not have damage, and the damage began to accumulate after $\varepsilon_{\text {th }}$. And equation (11) can be obtained from equation (10):

$$
\frac{1}{(1-D)}=\exp \left(\frac{\varepsilon-\varepsilon_{\mathrm{th}}}{a}\right)^{b} \text {. }
$$

Taking two times of the natural logarithm on both sides of equation (11) yields the following equation:

$$
\ln \left[\ln \left(\frac{1}{(1-D)}\right)\right]=b \ln \left(\frac{1}{a}\right)+b \ln \left(\varepsilon-\varepsilon_{\mathrm{th}}\right) .
$$

Table 6 tabulates the results of numerical fitting of parameters $a$ and $b$ through the test data.

Figure 10 shows the $D-\varepsilon$ curve, fitted by the data from Table 4 and Table 6 , for A3 A6 specimens at an impact load of $0.3 \mathrm{MPa}$. It can be seen that the $D$ value of A6 was the largest, and that of A5 was the smallest at the same strain. It indicates that the space network which was similar to steel bars, formed by the lapping of fine and coarse fibers, had the best performance at this impact load. Figure 11 shows the fitted $D-\varepsilon$ curve data for A5 group specimens at different impact loading. As shown in Figure 11, when the impact load was $0.3 \mathrm{MPa}, D$ had the smallest value under the same strain, and the threshold strain was the largest. With the increase in the strain rate, more cracks are needed to dissipate energy, and the threshold strain would become small.

As aforementioned, the original HJC constitutive model was modified by introducing the static compressive strength influence factor $S_{f}$ into the yield surface equation, redefining the damage factor $D$ by using the three-parameter Weibull distribution from the perspective of random statistical and adjusting the function between the DCF and the strain rate. And the modified equation is shown as follows:

$$
\sigma^{*}=S_{f}\left[A(1-D)+\mathrm{BP}^{* N}\right]\left(m \lg \left(\dot{\varepsilon}^{*}\right)+n\right) \text {. }
$$

4.3. Numerical Calculation. Explicit nonlinear finite element software of LS-DYNA was used for SHPB numerical calculation in this paper. The HJC constitutive model was
TABLE 6: The fitting value of parameters $a$ and $b$ under different fiber hybridizations.

\begin{tabular}{lccccc}
\hline $\begin{array}{l}\text { Impact load } \\
\left(\mathrm{s}^{-1}\right)\end{array}$ & $\begin{array}{c}\text { Parameters } a \\
\text { and } b\end{array}$ & A3 & A4 & A5 & A6 \\
\hline 32.3 & $a$ & 0.0029 & 0.0024 & 0.0033 & 0.0025 \\
& $b$ & 1.224 & 1.161 & 1.423 & 1.391 \\
65.3 & $a$ & 0.0021 & 0.0058 & 0.0034 & 0.0042 \\
& $b$ & 1.225 & 1.301 & 1.193 & 1.138 \\
80.5 & $a$ & 0.0023 & 0.0049 & 0.0019 & 0.0018 \\
& $b$ & 1.026 & 1.325 & 1.142 & 0.94 \\
92.7 & $a$ & 0.0028 & 0.0032 & 0.0024 & 0.0036 \\
& $b$ & 1.282 & 1.238 & 0.879 & 1.172 \\
106.3 & $a$ & 0.0023 & 0.0037 & 0.0022 & 0.003 \\
& $b$ & 1.024 & 1.036 & 0.909 & 1.079 \\
\hline
\end{tabular}

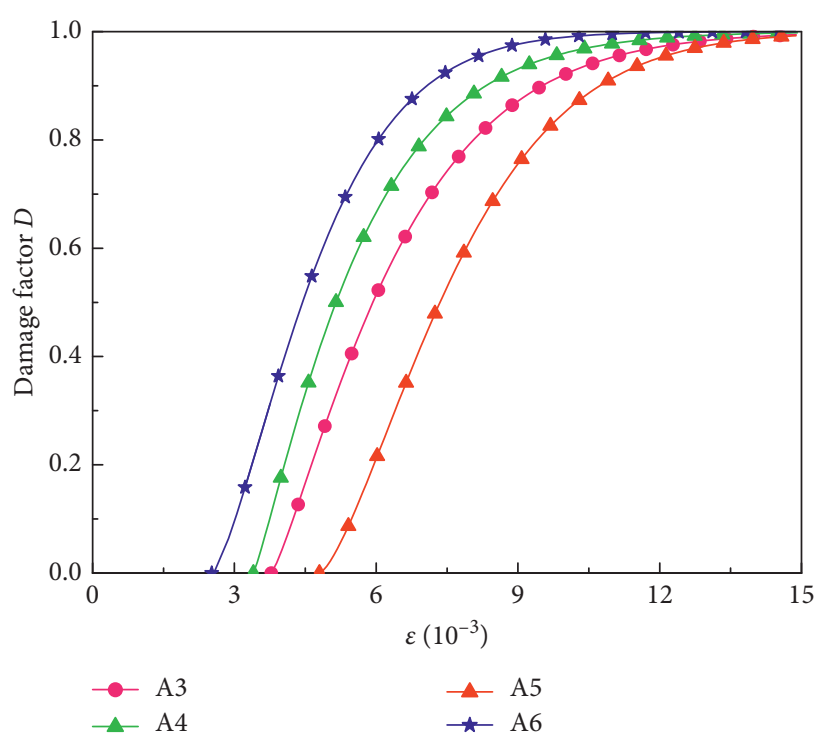

FIgURE 10: $D-\varepsilon$ curve of HPFRC under the same strain rate.

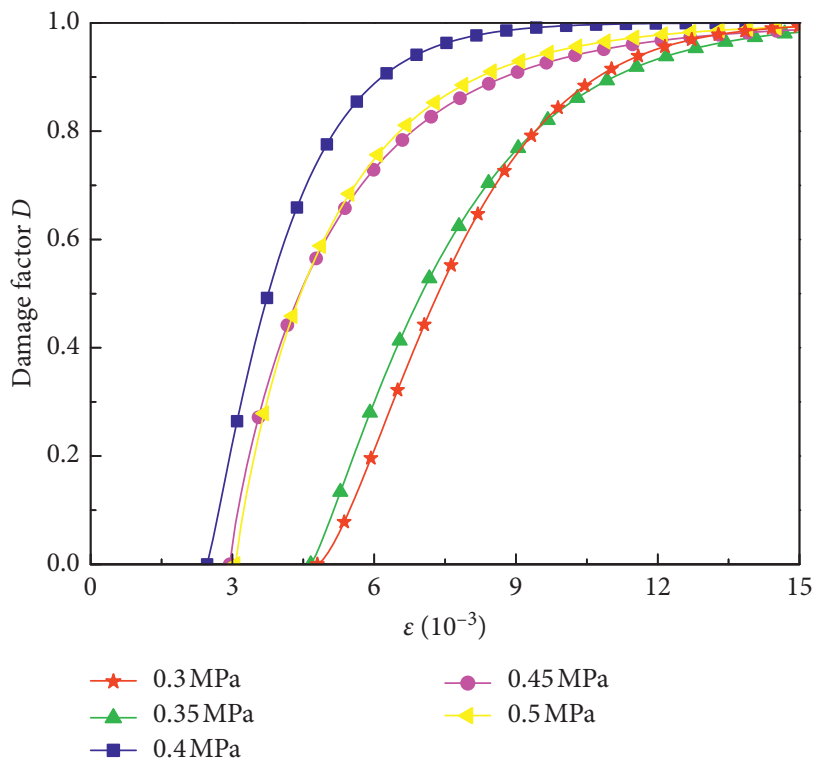

FIGURE 11: $D-\varepsilon$ curve of A3 under different strain rates. 

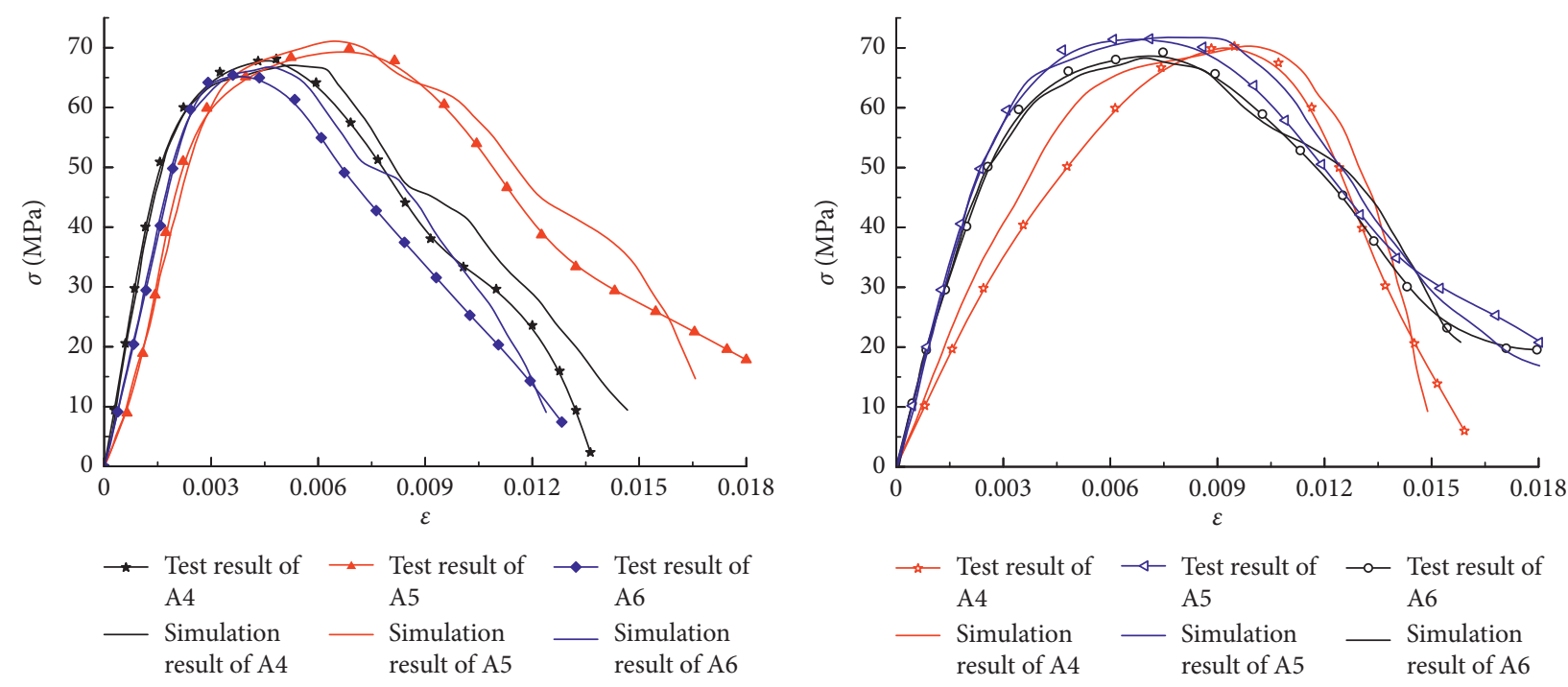

(a)

(b)
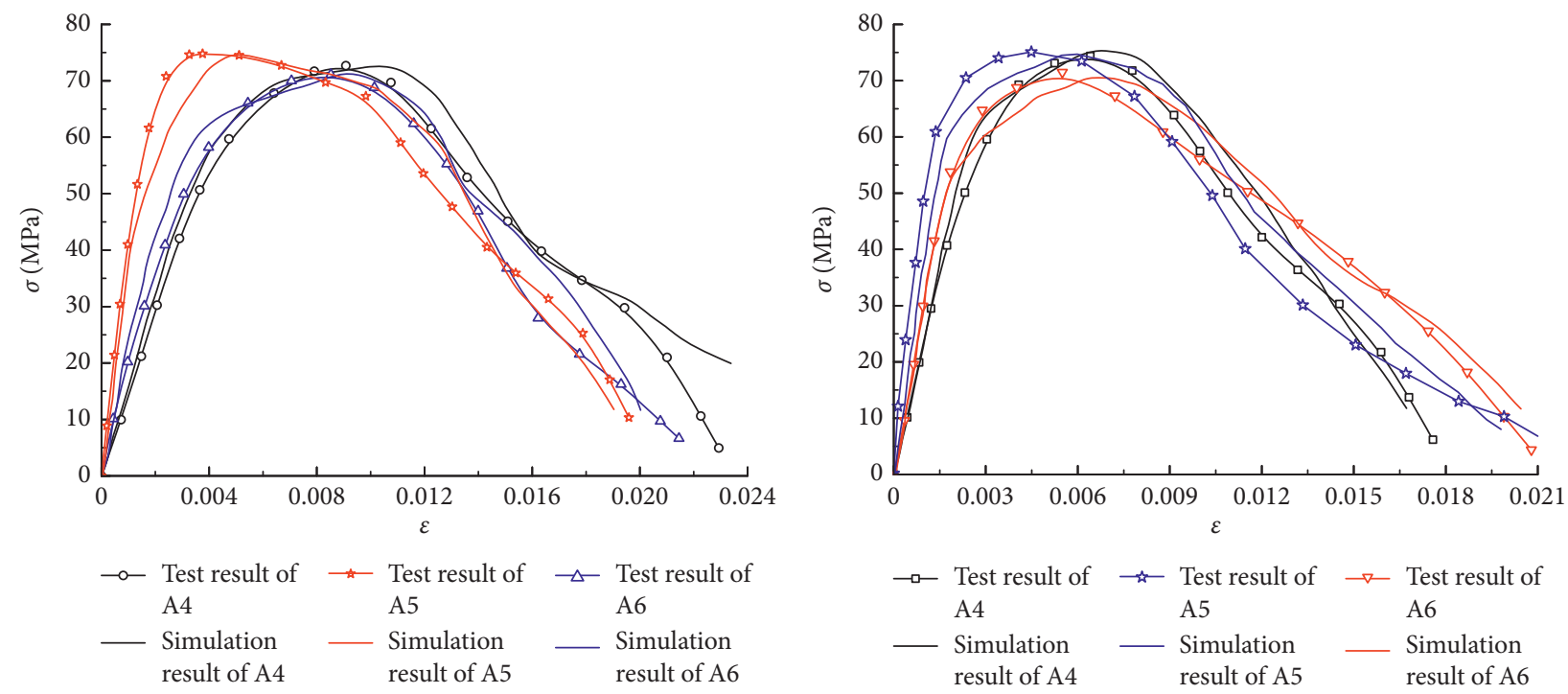

(c)

(d)

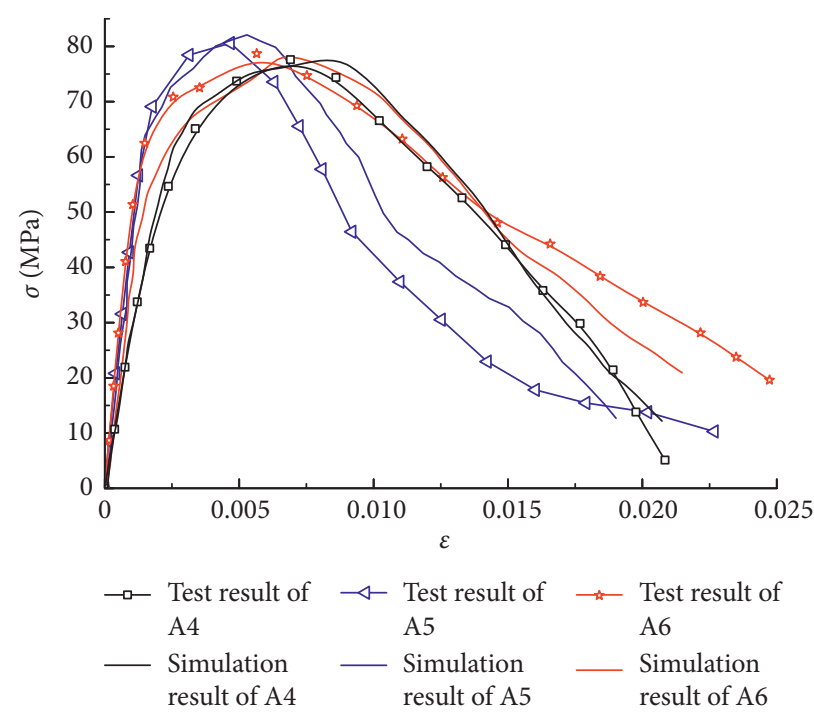

(e)

FiguRE 12: Comparison of stress-strain curves between test results and numerical simulation results: (a) $0.3 \mathrm{MPa}$, (b) $0.35 \mathrm{MPa}$, (c) $0.4 \mathrm{MPa}$ and (d) $0.45 \mathrm{MPa}$. 
TABle 7: Peak stress and peak strain for each specimen.

\begin{tabular}{lcccccccccccc}
\hline \multirow{2}{*}{ Specimen no. } & \multirow{2}{*}{ Results } & \multicolumn{2}{c}{$0.3 \mathrm{MPa}$} & \multicolumn{2}{c}{$0.35 \mathrm{MPa}$} & \multicolumn{2}{c}{$0.4 \mathrm{MPa}$} & \multicolumn{2}{c}{$0.45 \mathrm{MPa}$} & \multicolumn{2}{c}{$0.5 \mathrm{MPa}$} \\
& & $\sigma$ & $\varepsilon\left(10^{-3}\right)$ & $\sigma$ & $\varepsilon\left(10^{-3}\right)$ & $\sigma$ & $\sigma$ & $\varepsilon\left(10^{-3}\right)$ & $\sigma$ & $\varepsilon\left(10^{-3}\right)$ & $\sigma$ \\
\hline \multirow{4}{*}{ A4 } & TR & 68.13 & 4.824 & 70.25 & 9.476 & 72.69 & 9.076 & 74.38 & 6.411 & 77.6 & 6.905 \\
& NCR & 67.09 & 5.37 & 70.53 & 9.9 & 72.63 & 10.27 & 75.44 & 6.66 & 77.29 & 7.45 \\
& Error & 1.53 & 11.32 & 0.4 & 4.47 & 0.08 & 13.16 & 1.43 & 3.88 & 0.40 & 8.89 \\
A5 & TR & 69.85 & 6.871 & 71.5 & 7.103 & 74.78 & 3.76 & 75.09 & 4.486 & 80.6 & 4.67 \\
& NCR & 71.36 & 6.55 & 71.74 & 7.31 & 74.22 & 4.26 & 74.70 & 4.99 & 82.09 & 5.29 \\
& Error & 2.16 & 4.67 & 0.3 & 2.91 & 0.75 & 13.3 & 0.52 & 11.23 & 1.85 & 13.28 \\
A6 & TR & 65.43 & 3.607 & 69.28 & 7.475 & 71.11 & 8.522 & 71.49 & 5.498 & 80.6 & 4.67 \\
& NCR & 67.13 & 3.84 & 68.70 & 8.48 & 71.43 & 8.97 & 70.49 & 5.69 & 78.10 & 4.04 \\
& Error & 2.6 & 6.46 & 0.84 & 13.44 & 0.45 & 5.26 & 1.40 & 3.49 & 3.10 & 13.49 \\
\hline
\end{tabular}

Note. TR: test results; NCR: numerical calculation results.

embedded in LS-DYNA. A unified system of the unit was used in modeling: $\mathrm{mm}-\mathrm{g}-\mu \mathrm{s}$. Solid 164 element was used for three-dimensional HPFRC specimens, striker and pressure bars. The hourglass is controlled by increasing the bulk viscosity of the model because hourglass can easily lead to invalid calculation results. The striker and pressure bars were kept in the elastic stage, and material properties include density $7.85 \mathrm{~g} / \mathrm{cm}^{3}$, elastic modulus $2.1 \mathrm{e} 11 \mathrm{~Pa}$, and Poisson's ratio 0.3 . The dimension of the specimen model is consistent with the test specimen, and the modified HJC model was used for HPFRC; the effect of the fibers was considered into the concrete matrix parameters, and the related parameters are shown in Tables 3,5 , and 6 . The element length of the striker, incident bar, and transmission bar was $10 \mathrm{~mm}$ along the axial direction and was equally divided into 24 parts along the radial direction. The element length of the test piece along the axial unit was $5 \mathrm{~mm}$ and was equally divided into 48 parts along the radial direction. The contact surface between the striker and the incident bar, the incident bar and the specimen, and the specimen and the transmission bar adopts the contact of automatic surface to surface (ASTS).

When the HJC model was proposed, the original material parameters of conventional concrete were given, including $A=0.79, B=1.60$, and $N=0.61$. Firstly, the A6 group under different strain rates was simulated according to these original parameters, and the stress-strain curves and the test stress-strain curves were compared. The relevant parameters were adjusted to obtain the stress-strain curve under different strain rate conditions.

Figure 12 gives the stress-strain curves of the three groups of HPFRC specimens with different strain rates and the comparison between the simulation results and test results for the same specimen under different strain rates. Table 7 lists the peak stress and peak strain of numerical simulation and SHPB test by analyzing the results of stressstrain curves to compare the quality of numerical simulation. It can be seen that the modified HJC model in this paper was in good agreement with the stress-strain curve of HPFRC obtained from the SHPB test. For the peak stress, it can be seen from Table 7 that the overall error of the A4 A6 specimens is lower than $1 \%$, which was minimum when the impact load was $0.4 \mathrm{MPa}$. When the impact loading was $0.5 \mathrm{MPa}$, the relative error of the peak strain of the A6 specimen was $13.49 \%$, which was the maximum. The relative error of the peak stress of the A3 specimen was 3.10\%, which was the maximum. It indicated that the modified HJC model proposed in this paper could well describe the constitutive relationship of hybrid fine-coarse PPF-reinforced concrete materials.

\section{Conclusion}

In this study, the effect of the strain rate and fiber hybrid ratio upon the impact response was studied according to the SHPB device. The following conclusions were drawn:

(1) Both fine PPF and coarse PPF can improve the static strength of concrete, while the coarse PPF has a better enhancement effect. Besides, the proper hybridization of two sizes of PPF was more effective. Dynamic strength of the A6 group increased by $33.4 \%$.

(2) The SHPB tests indicate that the HPFRC is sensitive to the strain rate. The dynamic compressive strength, ultimate strain, and impact toughness of HPFRC increase with the increase in the strain rates. The DCF is approximately increasing linearly with the decimal logarithm of strain rate within the scope of test.

(3) Fiber hybrid quality ratio has a certain impact on the dynamic properties of HPFRC. Different sizes of PPF have a synergic effect at different levels. Appropriate fiber hybrid ratio can enhance the impact strength and toughness of concrete. In this study, the optimal fiber hybrid quality ratio is around $20 \%$.

(4) A modified dynamic damage model for HPFRC was proposed based on the HJC constitutive model, and the numerical calculation results were in good agreement with the SHPB test results, which indicated that the modified HJC model can be used to well describe the dynamic behavior of HPFRC.

\section{Data Availability}

The data used to support the findings of this study are available from the corresponding author upon request. 


\section{Conflicts of Interest}

The authors declare that they have no conflicts of interest.

\section{Acknowledgments}

This study was financially supported by the National Natural Science Foundation of China (Grant no. 41772319), the Chongqing Basic and Frontier Research Project (Grant no. cstc2018jscx-mszdX0071), and Chongqing Graduate Research and Innovation Project Funding (Grant no. CYS16005).

\section{References}

[1] V. J. John and B. Dharmar, "Influence of basalt fibers in the mechanical behavior of concrete-a review," Structural Concrete, pp. 1-12, 2020.

[2] N. Banthia and R. Gupta, "Hybrid fiber reinforced concrete (HyFRC): fiber synergy in high strength matrices," Materials and Structures, vol. 37, no. 10, pp. 707-716, 2004.

[3] M. Hsie, C. Tu, and P. S. Song, "Mechanical properties of polypropylene hybrid fiber-reinforced concrete," Materials Science and Engineering: A, vol. 494, no. 1-2, pp. 153-157, 2008.

[4] H. Zhang, L. Wang, L. Bai, M. Addae, and A. Neupane, "Research on the impact response and model of hybrid basaltmacro synthetic polypropylene fiber reinforced concrete," Construction and Building Materials, vol. 204, pp. 303-316, 2019.

[5] N. Banthia, F. Majdzadeh, J. Wu, and V. Bindiganavile, "Fiber synergy in hybrid fiber reinforced concrete (HyFRC) in flexure and direct shear," Cement and Concrete Composites, vol. 48, pp. 91-97, 2014.

[6] Y. Shi, T. Rabin, S. Feng, C. Mark, C. Tony, and S. Nagaratnam, "Use of macro plastic fibres in concrete: a review," Construction and Building Materials, vol. 93, pp. 180-188, 2015.

[7] S. M. S. Kazmi, M. J. Munir, Y.-F. Wu, I. Patnaikuni, Y. Zhou, and F. Xing, "Axial stress-strain behavior of macro-synthetic fiber reinforced recycled aggregate concrete," Cement and Concrete Composites, vol. 97, pp. 341-356, 2019.

[8] D. Li and S. Liu, "Macro polypropylene fiber influences on crack geometry and water permeability of concrete," Construction and Building Materials, vol. 231, pp. 117-128, 2020.

[9] T. Almusallam, S. M. Ibrahim, Y. Al-Salloum, A. Abadel, and H. Abbas, "Analytical and experimental investigations on the fracture behavior of hybrid fiber reinforced concrete," Cement and Concrete Composites, vol. 74, pp. 201-217, 2016.

[10] Y. Park, A. Abolmaali, M. Mohammadagha, and S. Lee, "Structural performance of dry-cast rubberized concrete pipes with steel and synthetic fibers," Construction and Building Materials, vol. 77, pp. 218-226, 2015.

[11] P. Smarzewski and D. Barnat-Hunek, "Effect of fiber hybridization on durability related properties of ultra-high performance concrete," International Journal of Concrete Structures and Materials, vol. 11, no. 2, pp. 315-325, 2017.

[12] N. K. Singh and B. Rai, "Assessment of synergetic effect on microscopic and mechanical properties of steel-polypropylene hybrid fiber reinforced concrete," Structural Concrete, pp. 1-19, 2020.

[13] Y. Al-Salloum, T. Almusallam, S. M. Ibrahim, H. Abbas, and S. Alsayed, "Rate dependent behavior and modeling of concrete based on SHPB experiments," Cement and Concrete Composites, vol. 55, pp. 34-44, 2015.

[14] H. Zhang, L. Wang, K. Zheng, T. J. Bakura, and P. G. Totakhil, "Research on compressive impact dynamic behavior and constitutive model of polypropylene fiber reinforced concrete," Construction and Building Materials, vol. 187, pp. 584-595, 2018.

[15] Q. M. Li and H. Meng, "About the dynamic strength enhancement of concrete-like materials in a split Hopkinson pressure bar test," International Journal of Solids and Structures, vol. 40, no. 2, pp. 343-360, 2003.

[16] R. Zhigang, C. Meng, L. Zhean, and X. Weiguo, "Dynamic mechanical property of hybrid fiber reinforced concrete (HFRC)," Journal of Wuhan University of Technology (Materials Science Edition), vol. 27, no. 4, pp. 783-788, 2012.

[17] S. M. Ibrahim, T. H. Almusallam, Y. A. Al-Salloum, A. A. Abadel, and H. Abbas, "Strain rate dependent behavior and modeling for compression response of hybrid fiber reinforced concrete," Latin American Journal of Solids and Structures, vol. 13, no. 9, pp. 1695-1715, 2016.

[18] Q. Fu, D. Niu, J. Zhang et al., "Dynamic compressive mechanical behaviour and modelling of basalt-polypropylene fibre-reinforced concrete," Archives of Civil and Mechanical Engineering, vol. 18, no. 3, pp. 914-927, 2018.

[19] Z. Li and Z. Liu, "Review of concrete dynamic constitutive model," Journal of Tianjin University Science \& Technology, vol. 48, no. 10, pp. 853-863, 2015, (in Chinese).

[20] Z. B. Ye, R. Y. Huang, Y. C. Li et al., "Steel fiber-reinforced concrete under impact loading dynamic constitutive equation," Construction and Building Materials, vol. 190, pp. 1049-1055, 2018.

[21] X. Yang, N. Liang, X. Liu, and Z. Zhong, "A study of test and statistical damage constitutive model of multi-size polypropylene fiber concrete under impact load," International Journal Of Damage Mechanics, vol. 28, no. 7, pp. 973-989, 2019.

[22] Y. Chi, M. Yu, L. Huang, and L. Xu, "Finite element modeling of steel-polypropylene hybrid fiber reinforced concrete using modified concrete damaged plasticity," Engineering Structures, vol. 148, pp. 23-35, 2017.

[23] N. Liang, J. Dai, and X. Liu, "Study on tensile damage constitutive model for multiscale polypropylene fiber concrete," Advances in Materials Science and Engineering, vol. 2016, Article ID 9168984, 6 pages, 2016.

[24] N. Liang, Q. Miao, X. Liu, and Y. Zhong, "Frost-resistance mechanism of multi-scale PFRC based on NMR," Magazine of Concrete Research, vol. 71, no. 13, pp. 710-718, 2019.

[25] Y. Wang, Z. Wang, X. Liang, and M. An, "Experimental and numerical studies on dynamic compressive behavior of reactive powder concretes," Acta Mechanica Solida Sinica, vol. 21, no. 5, pp. 420-430, 2008.

[26] X. Chen, L. Ge, J. Zhou, and S. Wu, "Experimental study on split hopkinson pressure bar pulse-shaping techniques for concrete," Journal of Materials in Civil Engineering, vol. 28, no. 5, 04015196 pages, 2016.

[27] W. Z. Zhong, A. Rusinek, T. Jankowiak, F. Abed, R. Bernier, and G. Sutter, "Influence of interfacial friction and specimen configuration in Split Hopkinson Pressure Bar system," Tribology International, vol. 90, pp. 1-14, 2015.

[28] Z. Wu, C. Shi, W. He, and D. Wang, "Static and dynamic compressive properties of ultra-high performance concrete (UHPC) with hybrid steel fiber reinforcements," Cement and Concrete Composites, vol. 79, pp. 148-157, 2017. 
[29] W. Wu, W. Zhang, and G. Ma, "Mechanical properties of copper slag reinforced concrete under dynamic compression," Construction and Building Materials, vol. 24, no. 6, pp. 910917, 2010.

[30] J. P. Romualdi and J. A. Mandel, “Tensile strength of concrete affected by uniformly distributed and closely spaced short lengths of wire reinforcement," ACI Structural Journal, vol. 61, pp. 27-37, 1964.

[31] J. A. Montoya, E. Díaz-Francés, and P. G. Figueroa, "Estimation of the reliability parameter for three-parameter Weibull models," Applied Mathematical Modelling, vol. 67, pp. 621-633, 2019. 